\title{
A STUDY TO ASSESS THE EFFECT OF INFORMATION BOOKLET ON LIFE STYLE MODIFICATION FOR PREVENTION OF MYOCARDIAL INFARCTION AMONG ADULTS OF SELECTED AREAS OF LUCKNOW CITY
}

\author{
Mrs. Sheela Rajeev Tiwari ${ }^{*}$ I Dr. C.P. Sharma** \\ ${ }^{*}$ Research Scholar, Himalayan University, Arunachal Pradesh, India. \\ ${ }^{* *}$ Research Guide, Himalayan University, Arunachal Pradesh, India. \\ DOI: http://doi.org/10.47211/tg.2020.v07iws01.004 \\ Received $14^{\text {th }}$ June 2020, Accepted $20^{\text {th }}$ June 2020, Available online $30^{\text {th }}$ June 2020.
}

\begin{abstract}
:
In this modern era millions of people follow an unhealthy lifestyle, hence they encounter illness, disability and even death. Cardiovascular Diseases are the number one cause of death globally. More people die annually from Myocardial Infarction than from any other cause .In India one of the major killer disease is Myocardial Infarction and the life style modification can improve the risk factors for Myocardial Infarction. Aim of the study: The lifestyle modification is one of the major issues in India. Modification of lifestyle behaviour can bring a significant decrease in incidence of Myocardial Infarction. The researcher felt the need to educate the people on life style modifications to prevent incidence of Myocardial Infarction. An evaluative one group pretest posttest was conducted to assess the effect of information booklet on life style modification for prevention of Myocardial Infarction among 60 samples of selected areas of Lucknow city. The information booklet which covered areas like causes of Myocardial Infarction, risk factors of Myocardial Infarction life style modification like dietary pattern, avoiding drinking and smoking habits and other healthy habits were discussed. The data analysis was done using descriptive and inferential statistics. The mean of pretest level of knowledge was 7.71with a standard deviation of 3.734.The mean of posttest level of knowledge was 18.55 with a standard deviation of .687.Calculated t value was 29.967 which was greater than the table value at 0.05 level of significance. There is a significant increase in knowledge after the administration of booklet which shows the booklet was effective in improving the knowledge of on life style modification for prevention of Myocardial Infarction.
\end{abstract}

KEYWORDS: Information booklet, Lifestyle Modification, Myocardial Infarction etc.

\section{ABOUT AUTHORS}

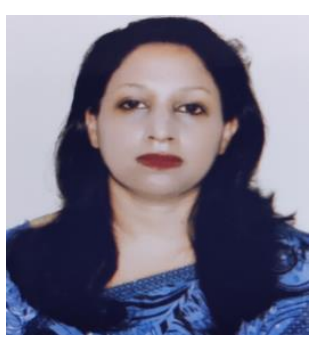

Author Mrs. Sheela Rajeev Tiwari is Ph.D. Research Scholar in Himalayan University, Arunachal Pradesh, India.

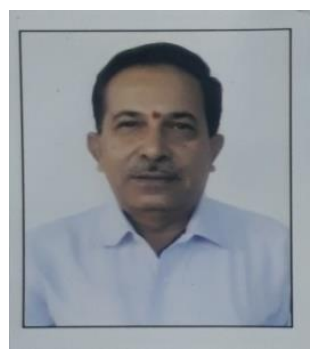

Author Dr. C. P Sharma M.Sc (N) Medical Surgical Nursing is Research Supervisor in Himalayan University, Arunachal Pradesh, India. 


\section{INTRODUCTION:}

Cardiovascular Diseases (CVDs) are the number one cause of death globally. More people die annually from CVDs than from any other cause. An estimated 17.5 million people died from CVDs representing $31 \%$ of all global deaths. Of these deaths, an estimated 7.4 million were due to coronary heart disease and 6.7 million were due to stroke(3). Over three quarters of CVD deaths take place in low- and middle-income countries. According to American Heart Association, coronary artery disease mortality rates will double from 1990 to 2020 , with approximately $82 \%$ of the increase attributable to the developing world. CVDs are the national burden as Non Communicable Diseases and a major public health issue. Coronary artery disease is caused by plaque buildup in the wall of the arteries that supply blood to the heart. Plaque is made up of cholesterol deposits. Plaque buildup causes the inside of the arteries to narrow over time. This process is called atherosclerosis. Coronary artery disease develops when the major blood vessels that supply heart with blood, oxygen and nutrients (coronary arteries) become damaged or diseased. Cholesterol-containing deposits (plaque) in the arteries and inflammation usually cause coronary artery disease.

When plaque builds up, it narrows the coronary arteries, decreasing blood flow to heart. Eventually, the decreased blood flow may cause chest pain (angina), shortness of breath, or other coronary artery disease signs and symptoms. A complete blockage can cause Myocardial Infarction. The most common form of CHD is the myocardial infarction (MI). MI occurs when a coronary artery is occluded or almost occluded, which creates a severe reduction in the blood flow, causing some of the heart muscle being supplied by that artery to become infarcted.(5)

Coronary heart disease is now the leading cause of death worldwide. An estimated 3.8 million men and 3.4 million women die each year from CHD. In developed countries heart disease is the leading cause of death in men and women. In Europe CHD accounts for an estimated 1.95 million deaths each year (2). Despite a remarkable decline in cardiovascular deaths over several decades, coronary heart disease (CHD) remains the leading cause of death in India. CHD mortality rates fell as much as $52 \%$ in men and $49 \%$ in women.

In India, studies have reported increasing CHD prevalence over the last 60 years, from $1 \%$ to $9 \%$ in urban populations and $<1 \%$ to $4 \%$ in rural populations. The risk factors identified are diabetes, tobacco smoking and hypertension. In 2013, the prevalence of MI in men was about three times higher than for women in the UK. The recent estimates of the incidence of $\mathrm{MI}$ in the USA are about 525,000 based on AHA data. (4). It is evident that $\mathrm{MI}$ is the leading cause of morbidity and mortality worldwide. It is responsible for over $15 \%$ of mortality each year. The prevalence of $\mathrm{Ml}$ is higher among men in all age-specific groups than women. . The modifiable risk factors account for more than $90 \%$ of the risk for acute MI. Nine risk factors such as dyslipidemia, smoking, psychosocial stressors, diabetes mellitus, hypertension, obesity, alcohol consumption, physical inactivity, and a diet low in fruits and vegetables were strongly associated with acute $\mathrm{MI}$ in the 52 countries (1). Hence the researcher felt the need to educate about the life style conditions which helps in the prevention of $\mathrm{MI}$

\section{STATEMENT OF THE PROBLEM:}

A study to assess the effect of information booklet on life style modification for prevention of Myocardial Infarction among adults of selected areas of Lucknow city.

\section{OBJECTIVES:}

- To identify existing knowledge related to lifestyle modification for the prevention of Myocardial Infarction.

- To determine the effect of booklet related to lifestyle modification for the prevention of Myocardial Infarction.

- To find an association between the level of knowledge of adults and selected demographic variables.

\section{DEFINITIONS OF TERMS AND VARIABLES:}

ASSESS: 'refers to gathering information for evaluation of knowledge related to lifestyle modification for the prevention of Myocardial Infarction

EFFECT: refers to determining the extent to which the booklet has achieved the desired effect as expressed by gain in knowledge related to lifestyle modification for the prevention of Myocardial Infarction

ADULTS: refers grown up, mature, adult male or female person. 


\section{METHODOLOGY:}

Research Methodology refers to controlled investigations of the ways of obtaining, organizing and analyzing data. It addresses the development, validation and evaluation of research tools or techniques.

\section{Research Approach}

The research method adopted for the present study was descriptive evaluative approach as the study aimed at development of an intervention (booklet on lifestyle modification for prevention of Myocardial Infarction) for adults, of selected areas of Lucknow and determining its effectiveness statistically. This approach would help the investigator to evaluate the effect of the specific intervention that is 'effect of booklet' on the variable that is 'knowledge' of adults on lifestyle modification for prevention of Myocardial Infarction.

\section{Research Design}

Quasi experimental (one group) pre-test and post-test design.

\section{VARIABLES:}

\section{Independent Variable}

The independent variable is booklet on lifestyle modifications on myocardial Infarction.

\section{Dependent Variable}

The dependent variable is knowledge of adults regarding lifestyle modification on Myocardial Infarction.

\section{Setting}

The present study was conducted in Ashiyana area of Lucknow,U.P

\section{Population}

The population comprises of adults above 30 years of age.

\section{Sampling}

Sample size is 60

Sampling Technique

Non probability purposive sampling was adopted

Sampling Criteria

Inclusion Criteria

- Adults who are willing to participate.

- Adults who know to read and write hindi and English

- Adults above 30 years old

Exclusion Criteria

- Adults who are health care professional.

\section{DEVELOPMENT OF TOOL:}

A self-structured questionnaire was developed for assessing the knowledge related to lifestyle modification on prevention of Myocardial Infarction. For the selection of the items and preparation of the tool the following steps were taken.

Review of research and non-research literature was conducted in the area related to lifestyle modification on prevention of Myocardial Infarction. Opinion and suggestions were taken from experts, which helped in determining the important areas to be included.

\section{DESCRIPTION OF THE TOOL:}

The Structured Questionnaire consists of two sections:

Section A: This section is the first section seeking information on demographic background of adults i.e. age of sample, gender, religion educational status, family income, dietary pattern etc. It consists of total 11 questions.

Section B: This section is the second part of self-structured questionnaire, which consists of questions assessing knowledge about lifestyle modifications on prevention of MI. The questions on the following.

1. Knowledge on Myocardial Infarction.

2. Risk factors on MI.

3. Prevention of MI.

4. Life style modifications on prevention of MI.

There are a total of 30 questions in the questionnaire, Item number 1-5 inquire to knowledge of heart, item number 6-10 related to awareness of $\mathrm{MI}$, item number 11-15 risk factors of $\mathrm{MI}$, item number 16-20 on prevention of $\mathrm{MI}$, 21-25 regarding dietary modification of $\mathrm{MI}$, Item number 26-30 on lifestyle modification on prevention of $\mathrm{MI}$. 
SCORING:

There were four options given for the questionnaires. The scoring for correct answer was ' 1 ' and for the wrong answers were ' 0 '. The scores range from a minimum of zero to a maximum score of 30 .

The levels of knowledge have been classified as:

- $\quad$ Poor (0-10)

- Average (11-20)

- $\operatorname{Good}(21-30)$

\section{PROCEDURE FOR DATA COLLECTION:}

Objectives of the study were discussed and consent for participation in the study was taken from the selected group. The investigator assured the subjects about the confidentiality of the data. The investigator himself administered the self-structured questionnaire for the pre-test. The duration of data collection for each sample was 15 to 20 minutes. The teaching was disseminated to the group after the pre-test and a brief introduction.

The instruction about post-test was given to the participants of experimental group. The post-test was conducted on $7^{\text {th }}$ day respectively after supplementing them with booklet. Time taken for post-test by each sample was 15 minutes approximately.

\section{RESULTS AND DISCUSSIONS:}

The data was analysed based on the following objectives.

1. To identify existing knowledge related to lifestyle modification for the prevention of Myocardial Infarction

2. To determine the effect of booklet related to lifestyle modification for the prevention of Myocardial Infarction.

3. To find an association between the level of knowledge of adults and selected demographic variables.

\section{ORGANIZATION OF STUDY FINDINGS}

The collected data is tabulated, analysed, organized and presented under the following headings.

SECTION I: It deals with the analysis of the demographic data of the samples like age, educational status, religion monthly income and occupation.

SECTION II: It deals with the analysis of data related to knowledge scores before and after administering the booklet.

SECTION III: It includes analysis of data related to effectiveness of teaching related to lifestyle modification on prevention of MI.

SECTION IV: It includes analysis of data to find the association between selected demographic variables such as age, educational status, occupation, and economical status.

The data presented in table 1 shows that in the experimental group of the study, majority (30\%) of the adults fall in the age group of above 60 Years, $22 \%$ fall in the category of $30-40$ years, $23 \%$ in the age group of $40-50$ years and $25 \%$ fall in the category of $50-60$ years.60\% are male participants and $40 \%$ are female participants. $91 \%$ of participants belong to Hindu religion.

The greater part (30\%) of adults has an educational status up to graduation. Only $3 \%$ are illiterate. The occupation of the participants comprises of $33 \%$ are salaried, $22 \%$ retired, $8 \%$ business and $4 \%$ home makers. Majority of participants are vegetarians (57\%).35\% are no vegetarians. Study participants $35 \%$ have a habitual history of alcohol intake.23\% cigarette smoking, $20 \%$ tobacco chewing, and $13 \%$ with consumption of junk foods and around $8 \%$ with all the above habitual history. $37 \%$ of study participants have a history of hypertension and $23 \%$ with diabetes mellitus.

The demographic data of the study also reveals that $70 \%$ of study participant have no information on lifestyle modification on prevention of MI. 30\% have information on lifestyle modification on prevention of MI from mass media, $22 \%$ got the information from friends and relatives and only $13 \%$ have the information from medical people. 


\section{ARTICLES}

\section{SECTION I}

Table 1: Frequency and percentage of socio demographic characteristics

\begin{tabular}{|c|c|c|c|}
\hline S. NO. & CHARACTERISTICS & FREQUENCY & PERCENTAGE \\
\hline 1 & $\begin{array}{l}\text { Age } \\
30-40 \\
40-50 \\
50-60 \\
\text { Above } 60\end{array}$ & $\begin{array}{l}13 \\
14 \\
15 \\
18\end{array}$ & $\begin{array}{l}23 \\
23 \\
25 \\
30\end{array}$ \\
\hline 2 & $\begin{array}{l}\text { Gender } \\
\text { Male } \\
\text { Female }\end{array}$ & $\begin{array}{l}36 \\
24\end{array}$ & $\begin{array}{l}60 \\
40\end{array}$ \\
\hline 3 & $\begin{array}{l}\text { Educational Status } \\
\text { Illiterate } \\
\text { Primary } \\
\text { High school } \\
\text { Graduate } \\
\text { Post graduate }\end{array}$ & $\begin{array}{l}02 \\
09 \\
17 \\
18 \\
14\end{array}$ & $\begin{array}{l}03 \\
15 \\
28 \\
30 \\
23\end{array}$ \\
\hline 4 & $\begin{array}{l}\text { Occupation } \\
\text { Salaried } \\
\text { Business } \\
\text { Homemaker } \\
\text { Retired } \\
\text { Unemployed } \\
\end{array}$ & $\begin{array}{l}20 \\
05 \\
18 \\
13 \\
04\end{array}$ & $\begin{array}{l}33 \\
08 \\
30 \\
22 \\
06\end{array}$ \\
\hline 5 & $\begin{array}{l}\text { Residential Area } \\
\text { Urban } \\
\text { Rural }\end{array}$ & $\begin{array}{l}40 \\
20\end{array}$ & $\begin{array}{l}67 \\
33\end{array}$ \\
\hline 6 & $\begin{array}{l}\text { Type of family } \\
\text { Nuclear } \\
\text { Joint }\end{array}$ & $\begin{array}{l}42 \\
18\end{array}$ & $\begin{array}{l}70 \\
30\end{array}$ \\
\hline 7 & $\begin{array}{l}\text { Diet Preference } \\
\text { Vegetarian } \\
\text { Non Vegetarian } \\
\text { Egg vegetarian }\end{array}$ & $\begin{array}{l}31 \\
24 \\
05\end{array}$ & $\begin{array}{l}57 \\
38 \\
05\end{array}$ \\
\hline 8 & $\begin{array}{l}\text { Habitual history } \\
\text { Cigarette smoking } \\
\text { Alcohol consumption } \\
\text { Tobacco chewing } \\
\text { Junk food } \\
\text { All of the above }\end{array}$ & $\begin{array}{l}14 \\
21 \\
12 \\
08 \\
05\end{array}$ & $\begin{array}{l}23 \\
35 \\
20 \\
13 \\
08\end{array}$ \\
\hline 9 & $\begin{array}{l}\text { Medical history } \\
\text { Diabetes Mellitus } \\
\text { Hypertension } \\
\text { Heart disease } \\
\text { Any others }\end{array}$ & $\begin{array}{l}14 \\
22 \\
07 \\
17\end{array}$ & $\begin{array}{l}23 \\
37 \\
12 \\
28\end{array}$ \\
\hline 10 & $\begin{array}{l}\text { Do you have information on } \\
\text { prevention of } \mathrm{MI} \\
\text { Yes } \\
\text { No }\end{array}$ & $\begin{array}{l}18 \\
42\end{array}$ & $\begin{array}{l}30 \\
70\end{array}$ \\
\hline 11 & $\begin{array}{l}\text { If Yes } \\
\text { Books/Newspaper/Magazine } \\
\text { Mass Media } \\
\text { Friends } \\
\text { Family members } \\
\text { Health care Professional }\end{array}$ & $\begin{array}{l}12 \\
18 \\
09 \\
13 \\
08\end{array}$ & $\begin{array}{l}20 \\
30 \\
15 \\
22 \\
13\end{array}$ \\
\hline
\end{tabular}




\section{SECTION -II}

It deals with the analysis of data related to knowledge scores before and after administering the booklet on lifestyle modification on prevention of Myocardial Infarction.

Table 2. Pretest and post test scores of each category of knowledge on Myocardial Infarction

\begin{tabular}{|c|c|c|c|c|c|c|}
\hline \multirow[t]{2}{*}{ S.No. } & \multirow{2}{*}{ Areas } & \multicolumn{2}{|c|}{ Pre-test knowledge score } & \multicolumn{2}{|c|}{ Post-test knowledge score } & \multirow{2}{*}{$\begin{array}{l}\text { Paired } \\
\text { ' } t \text { ' value }\end{array}$} \\
\hline & & Mean & SD & Mean & SD & \\
\hline 1 & $\begin{array}{c}\text { Knowledge on of } \\
\text { Myocardial Infarction }\end{array}$ & 1.95 & 1.274 & 4.84 & .368 & -23.815 \\
\hline 2 & $\begin{array}{c}\text { Risk factors on } \\
\text { Myocardial Infarction }\end{array}$ & 1.63 & 1.261 & 4.86 & .427 & -25.273 \\
\hline 3 & $\begin{array}{c}\text { Prevention of } \\
\text { Myocardial Infarction }\end{array}$ & 2.17 & 1.326 & 4.930 & .2564 & -21.047 \\
\hline 4 & $\begin{array}{l}\text { Lifestyle modifications } \\
\text { on prevention of } \mathrm{MI}\end{array}$ & 1.96 & 1.294 & 4.90 & .333 & -23.755 \\
\hline
\end{tabular}

Table No: 2 shows that Pretreatment knowledge regarding knowledge on causes of Myocardial Infarction, risk factors of myocardial infarction, Prevention of Myocardial Infarction, lifestyle modifications on prevention of $\mathrm{Ml}$ the average score has been improved after administering information booklet. Researcher applied paired $\mathrm{t}$ test in each. Since $p$ value is less than 0.05 ( $p$ value $=0.000$ ) with 59 degrees of freedom at $5 \%$ level of significance there is significant rise in average knowledge score regarding each section related to Myocardial Infarction.

\section{SECTION -III}

This section deals with the pretest scores and post test scores and thereby assessing the effect of booklet on lifestyle modification for the prevention of Myocardial Infarction.

There were 60 samples taken for study. Each of them has to answer 30 questions. Their pre and post-test correct answers were recorded and mean and standard deviation of the test scores are obtained as below:

Table 3. Pre test and post test knowledge score

Table 3. Pre test and post test knowledge score
\begin{tabular}{|c|c|c|c|c|c|}
\hline Phase & Mean Score & S.D. & $\begin{array}{c}\text { Paired 't' } \\
\text { test }\end{array}$ & Df & P value \\
\cline { 1 - 3 } Pre-test & 7.71 & 3.734 & -29.967 & 59 & .000 \\
\hline Post-test & 18.55 & .687 & & & \\
\hline
\end{tabular}

It has been observed that pretreatment knowledge average score is 7.71 and after teaching average knowledge score rises to 18.55. To check whether this rise in average knowledge score is statistically significant or not, researcher applied paired t test. Since $p$ value is less than 0.05 ( $p$ value $=0.000$ ) there is significant difference in average knowledge score after giving booklet. Researcher can conclude that at $5 \%$ level of significance there is significant rise in average knowledge score after teaching. This indicates that the booklet is effective in increasing the knowledge of the samples related to lifestyle modification for the prevention of Myocardial Infarction. Hence $\mathrm{Ho}$ is rejected and $\mathrm{H} 1$ is accepted.

\section{SECTION- IV}

This section deals with the association of knowledge score related to importance of eye donation with demographic variables like age, education, , gender, occupation, type of family etc.

Chi-square test used to find out association between knowledge and selected demographic variables like age, gender, educational status, occupation ,type of family etc. It was found that the chi square value obtained was greater than the calculated value which indicates no significant association between knowledge score and demographic variables.

\section{CONCLUSION}

One of the biggest contributors to coronary diseases is unhealthy life style. Lifestyle modification is the only best defense against heart disease. Myocardial Infarction is the leading cause of death. The incidence of myocardial infarction is very high, but majority of population does not follow lifestyle modification which is a modifiable risk factor which can prevent myocardial infarction. Hence the researcher felt the need to study the topic. The study findings reveal that very few get information from health professionals which show that there is need for health sectors to focus on primary prevention of cardiovascular diseases. Providing the general 


\section{ARTICLES}

public with information and teaching them by health care professional can reduce the incidences to a great extent(6). The present study has great implications in clinical practice as the medical and nursing staff can provide information to clients regarding lifestyle modifications to prevent Myocardial Infarction. Also this study has implications in nursing education as it provides motivation for the nursing students to conduct research in these areas.

The study has implications in nursing administration as further scope of studies are there in rural areas.

\section{REFERENCES:}

1) Aparna C, Jyothi lakshmi S .2019.Knowledge regarding early symptoms and Management of Myocardial Infarction among high risk clients. International Journal of Cardiovascular Nursing 5(2),610

2) Dahal P, karki R. Knowledge and Practice regarding prevention of Myocardial Infarction among visitors of Sahid Gangalal national heart centre, Kathmandu, Nepal. Diabetes Management 2017. 7(2). 240246

3) Jenna Brinks . Amy Fowler et al . Lifestyle Modification in Secondary Prevention. American Journal of lifestyle Medicine. 2017 11(2): 137-152.

4) Mahmoud M .Sabah Nazeh.2018.IJSN: Effect of Lifestyle Modification Intervention on Health Status of Coronary Artery Disease Patients: Randomized Control .http://journal.julypress.com/index.php/ijsn v3i3.523(accessed April 2020)

5) Suresh K. Sharma. Lippincot Manual of Medical Surgical Nursing, $10^{\text {th }}$ Edition, New Delhi, Walters Kluwer Pvt. Ltd., 2016, pp. 378-384.

6) Zagade T. Patil A. Effectiveness of self-instructional module on knowledge regarding prevention of microvascular and macrovascular complications among patients with diabetes mellitus. International Journal Science Research.2014. 3(5).902-908 